\title{
Leveraging Publicly Available Building Energy Data as a Design Firm in the United States
}

\author{
Stephen D. Ray ${ }^{1,2}$, Luke Leung ${ }^{2}$, Arathi Gowda ${ }^{2}$ and Niancen Miao $^{2}$ \\ 1. Department of Physics and Engineering, North Park University, Chicago IL 60625, USA \\ 2. Skidmore, Owings and Merrill LLP, Chicago IL 60604, USA
}

\begin{abstract}
Publicly available building energy data are exploding — thirteen American cities and 14 states now require them by law. This emergence of data nudges building owners and tenants to reduce energy consumption by comparing their usage to that of similar buildings. However, vast untapped energy reductions and deeper physical understandings can still be extracted from these data. This paper extends the energy saving impact and provides key insight into building performance through publicly-disclosed data by describing three initiatives at a large design firm. An internal high performance design reporting program compares projects from around the world and across offices. A case study of 706 buildings in New York City illustrates the value of tracking large-scale patterns to a design firm. Per capita energy and carbon usage is correlated to life expectancy to better inform neighborhood and city design. As more data freely flow out into the public, engineers must strategically engage it.
\end{abstract}

Key words: High performance buildings, tall buildings, big data, life expectancy.

\section{Introduction}

June 1, 2014 marked the first compliance deadline of the Chicago Building Energy Use Benchmarking Ordinance. As of July 2015, Chicago joins 13 other US cities that require certain commercial buildings to report building energy usage data in hopes of reducing energy consumption. Benchmarking data along with other large datasets of measured building energy use, such as the CBECS (Commercial Buildings Energy Consumption Survey) and the DOE (Department of Energy's) Buildings Performance Database, offer overwhelming amounts of information on actual building performance. These data on their own are akin to tombs of notes awaiting a musician's interpretation and performing. This paper describes a few ways where a large design firm makes music out of the vast, publicly available datasets through internal high performance design goals, informing tall building design with data from New York City, and considering

Corresponding author: Stephen D. Ray, Ph.D., P.E., research fields: building energy, natural ventilation, computational fluid dynamics, thermal comfort and indoor air quality. a city's impact on life expectancies.

\section{Internal High Performance}

\subsection{Design Goals}

Publicly available data provide insight to large-scale trends in building energy use, which are discussed in subsequent sections. These data also have been used to inform key decision makers on individual projects within the firm. As part of a firm-wide initiative to compare every project to measure performance of similar buildings, internal HPD (high performance design) goals are tracked on each project, as shown in Fig. 1. The projects are compared to the 2003 CBECS results through the EPA (Environmental Protection Agency's) Target Finder as part of their ENERGY $\operatorname{STAR}^{\circledR}$ program $[1,2]$. Each project is compared to buildings of similar climate, gross floor area and building function within the 5,215 building CBECS database to generate an energy savings relative to CBECS. International project locations are first assigned a corresponding United States climate that can then be used for comparison with the CBECS data. 
These relative energy savings provide some measure of a normalized energy performance metric for projects around the world.

More importantly, the use of publicly available building energy data provides a standard measure of comparison between various offices within the firm. This comparison has motivated engineers and energy modelers within each of the offices to dive even further into the details of energy modeling best practices as they attempt to outperform their peers. The comparison also informs general modeling practices at various stages of the project phase. Should projects that only last through schematic design be treated differently than projects that last through construction documents? As shown in Fig. 1, projects in $\mathrm{CD}$ (construction documents) phase tended to perform best across all offices. One might argue much of the uncertainty which has been removed from the model by the time $\mathrm{CD}$ is reached, but such explanation does not explain the subsequent drop in performance for buildings in CA (contract administration) phase. Furthermore, the energy model is not always updated at every stage of design, so the increase in performance may simply be explained by the particular buildings in $\mathrm{CD}$ during the considered year. Ongoing comparisons across multiple years are needed for a more thorough analysis. The comparison, perhaps most importantly, provides bragging rights to directors and partners across the firm and raises awareness of energy performance for key decision makers. Moving forward, the firm believes this internal competition should be encouraged to better integrate engineering and architectural design using performance metrics and the forms they inspire.

Limitations to this methodology shown in Fig. 1 inform how broadly results are applied. One of the biggest limitations comes from the energy model used to simulate the energy consumption of each project. Increasing levels of detail are used in the energy model as a project progresses and not all projects go through the same phase. A more general issue with energy models also affects results: modeling variability. Each modeler works slightly differently, which adds to the uncertainty of the simulated results. More standardized energy modeling practices and the development of more sophisticated energy models that track uncertainties, such as the ongoing work at Argonne National Labs, will help reduce skewed comparisons between projects that may be influenced by modeling

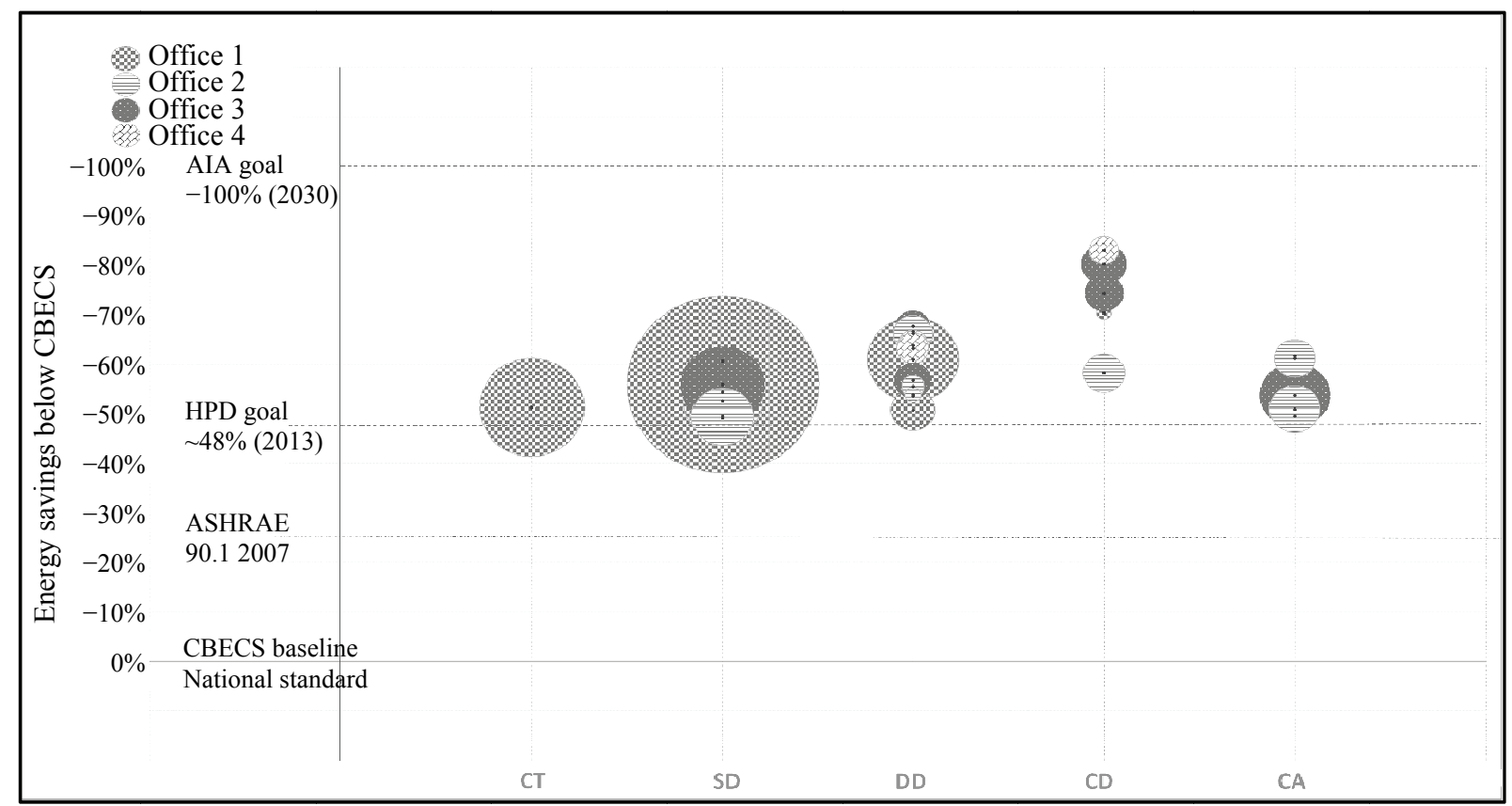

Fig. 1 Plot of project energy savings below similar buildings in CBECS across four offices of a large design firm. Project phase is plotted on the horizontal axis and bubble size corresponds to project gross floor area. 
practices more than actual design [3].

Other limitations arise from using CBECS data. Of the 5,215 buildings in CBECS, 95\% have a gross floor area of $50,000 \mathrm{ft}^{2}$ or less and $90 \%$ are two-story or one-story buildings [2]. No buildings over 1,000,000 $\mathrm{ft}^{2}$ are included [2]. Given the scale of projects at a large architecture firm, a database that includes larger buildings could broaden the application of such standardized comparisons. An additional limitation of this methodology is its use in international projects. For instance, comparable data are not available for projects in China which is problematic given that $38 \%$ of global floor space growth is being projected in China from 2015 to 2035 [4]. Even though climate information is used to correlate international projects to buildings in similar American climates through CBECS, other factors that may vary with country and affect energy consumption are not controlled. Factors, like code requirements, comfort norms, construction practices and occupancy patterns, all affect building energy consumption and can vary from nation to nation. All of these factors complicate the firm's initial efforts to compare EUI (energy usage intensity) in various geographic markets, while helping to prioritize the need for energy modeling and benchmarking as the global engineering community continues to develop its understanding of building energy performance.

\subsection{New York City Data in Tall Building Design}

\subsubsection{Tall Building Energy Usage}

In 2009, New York City was the first city in the United States to require large buildings to publicly release energy consumption data by passing New York City Local Law 84. Although the city analyzes these data annually and releases various reports, the particular comparisons and analyses most useful to the firm were not considered-particularly the performance of tall and super tall buildings. Exploring the data internally not only strengthened internal frameworks on the energy usage of tall buildings, but also provided insight into a rating system commonly pursued by clients.

The analyzed data were collected by the City of New York in 2012 and released in September 2013 [5]. Unfortunately, the city does not release any direct measure of building height in their energy benchmarking data, but the Department of City Planning does through the PLUTO (Primary Land Use Tax Lot Output) [6]. The PLUTO data used in this study were collected between February and May 2013 [6].

The data have been cleaned to remove any building with incomplete data or large outliers, which likely resulted from poor data collection. While numerous confounding factors impact building energy consumption, some care is taken to eliminate as many factors as possible. Since all of the data are collected in New York City over the same year, the same weather conditions applied to all the buildings. Only office buildings with at least $80 \%$ of their gross floor area used as office space are considered to minimize the confounding factor of building use. The total number of buildings that meet all these criteria and are used in this study is 706. Energy usage is measured using site EUI in the units of $\mathrm{kBtu} / \mathrm{ft}^{2} / \mathrm{yr}$, which is calculated by dividing the entire building site energy in one year by the total floor area.

These measured data are considered alongside predicted EUI values from the DOE's ENERGY STAR program. Using the same 2003 CBECS data, they have performed various regressions to identify the six strongest predictors of building energy use, which include gross floor area, cooling degree days and heating degree days [7]. Despite the ENERGY STAR program's reporting source EUI, it converts the site EUI inputted into portfolio manager using constant source-site ratios across the country [7]. Electricity purchased from the grid and natural gas use ratios of 3.14 and 1.05 , respectively [7]. Site energy intensity is also preferred because it allows for a better comparison between building characteristics, which is more aligned with the goals of this paper than source energy 
considerations. Climate data from New York City and San Francisco are used to generate a predicted EUI versus gross floor area curve.

As shown in Fig. 2, shorter buildings consume less energy per unit area on average than taller buildings. While the EUI of buildings from 0 to 29 floors steadily increases with elevation, a distinct jump is observed at 30 39 floors, after which a plateau is reached for taller buildings. The average EUI of buildings with 10 19 floors increases by $33 \%$ as compared to buildings with 30 39 floors. An increase in 20 floors leads to $33 \%$ more energy consumption. With the same increase of 20 floors from 30 to 39 to more than 50 floors, the average EUI actually slightly decreases by $3 \%$ after reaching the plateau at 30 39 floors. The predicted EUI from the DOE's correlation also predicts a plateau for larger buildings. Although their correlation does not include a direct measure of building height, the gross floor area serves as a reasonable proxy.

This plateau is consistent with a firm-wide internal framework for tall building energy usage. Above 30 40 floors, much of the lost chilled-water efficiency from introducing a heat exchanger in a pressure break is already incurred. Sky view factors will also typically not increase with elevation past 30 39 floors, since most buildings of that height are already exposed to a large sky. Wind speeds also do not increase as rapidly at higher elevations. According to ASHRAE (American Society of Heating, Refrigeration and Air Conditioning Engineers), a local wind speed of $5.5 \mathrm{~m} / \mathrm{s}$ at $40 \mathrm{~m}$ (approximately the 10th floor) increases by $27 \%$

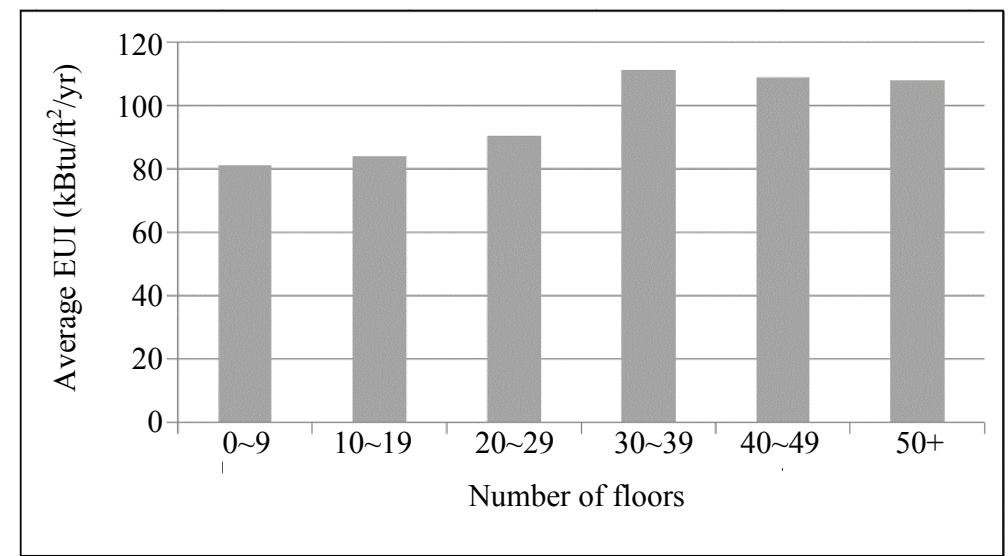

(a)

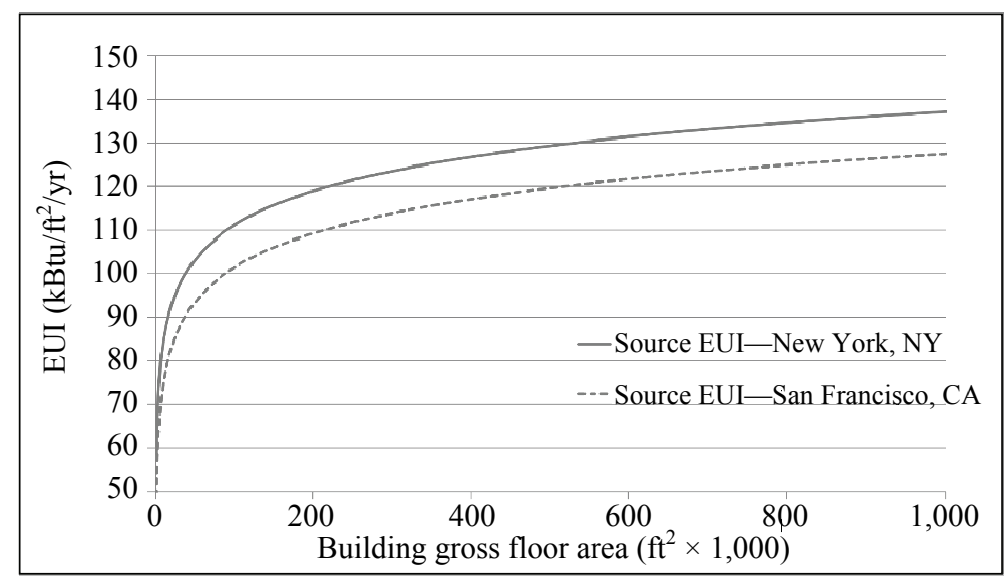

(b)

Fig. 2 Comparison between building characteristics: (a) average site EUI (units in $\mathbf{k B t u} / \mathrm{ft}^{2} / \mathrm{yr}$ ) of New York office buildings reported by the City of New York as a function of total number of floors; (b) predicted site EUI (units in $\mathrm{kBtu} / \mathrm{ft}^{2} / \mathrm{yr}^{2}$ ) as a function of building gross floor area from the DOE. 
to $7.0 \mathrm{~m} / \mathrm{s}$ at $120 \mathrm{~m}$ (the 30 th floor), while the $7.0 \mathrm{~m} / \mathrm{s}$ local speed at $120 \mathrm{~m}$ only increases by $12 \%$ to $7.8 \mathrm{~m} / \mathrm{s}$ at $200 \mathrm{~m}$ (the 50th floor) [8]. Aerosol levels and moisture content similarly vary less at higher elevations, as they are further away from the pollutant and moisture sources at ground level.

While these factors alone do not fully account for the observed trend, they contribute to an explanation. Another factor that may lead to higher EUIs in taller buildings is the fact that many financial institutions with energy dense trading floors and even onsite data centers typically occupy tall buildings. The 55-story Bank of America Tower is a well-known example of how financial institutions can require large plug loads that significantly impact the total building energy use [9]. Further investigation is required to confirm how systematic these large plug loads are in financial institutions and if the financial institutions in New York City occupy tall buildings. This issue relates to a larger conversation about building energy use: productivity. Rather than solely focus on the inputs to a building, should we not also consider the outputs to calculate some type of overall efficiency? An attempt to quantify this efficiency has been made by the building economic energy coefficient, but further development and dialog are needed to sufficiently vet the metric [10].

The 2013 report released by New York City shows newer office buildings consume more energy than older ones [11]. This same trend is reproduced in this study for office buildings lower than 25 floors, as shown in Fig. 3. However, buildings taller than 25 floors do not follow this trend, and those constructed after 1970 have actually, on average, been consuming less energy than those constructed between 1930 and 1970. Additionally, the difference between buildings taller and shorter than 25 floors has been decreasing over the decades. Renovations impact these numbers and are discussed in another paper [12].

These results have also helped reinforce internal frameworks for understanding the energy consumption of tall buildings. A more detailed explanation of this framework is presented elsewhere [12]. The framework considers unique features of tall buildings that lead to higher EUIs. For example, in taller buildings: elevators travel further distances at faster speeds; multiple pressure breaks in chilled and hot water lines increase pumping energy and reduce temperature differences of the water; infiltration can increase based on the stack effect and higher wind velocities; increased exposure to solar gains, because fewer surrounding buildings provide shading, can also increase cooling loads; larger internal loads from intense computing clusters require more electricity and cooling to offset heat gains. This framework provides a general understanding of tall buildings that has been

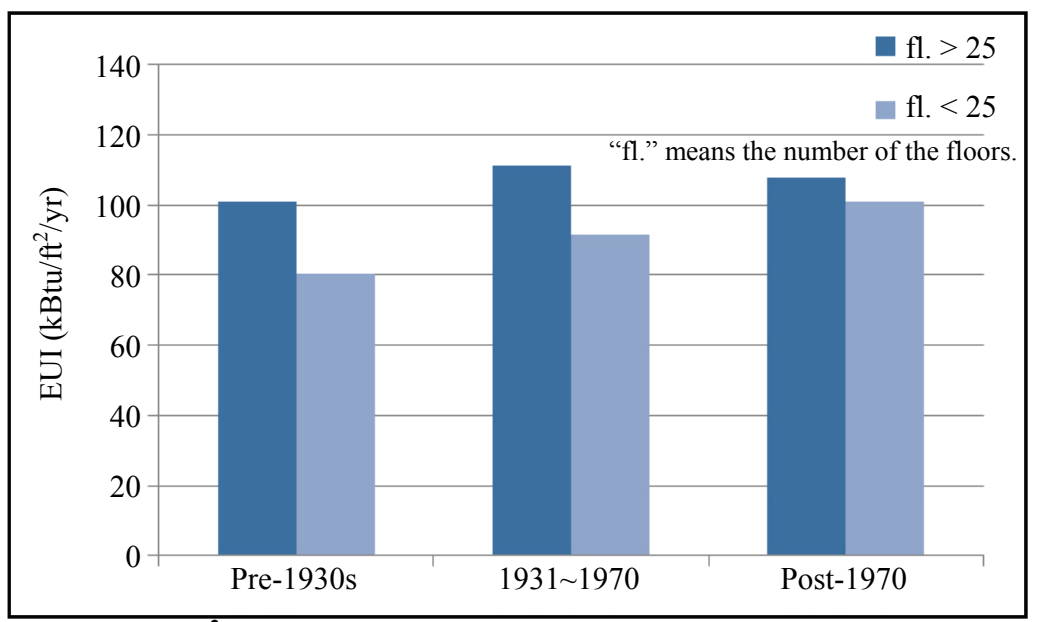

Fig. 3 Average EUI (units in $\mathrm{kBtu} / \mathrm{ft}^{2} / \mathrm{yr}$ ) of all office buildings with $80 \%$ or more official area as a function of various construction eras in New York subdivided by buildings below and above 25 floors. 
illustrated with both energy simulations and measured energy data. After surviving these vetting processes, the framework informs the foundation of tall building design used at the firm.

\subsubsection{Informing Rating System Use}

In addition to helping validate an internal tall building energy framework, these data from New York City can help inform the use of the ENERGY STAR rating system. Plotting the EUI as a function of ENERGY STAR rating, as shown in Fig. 4, shows a desirable trend for the EPA: Higher ENERGY STAR ratings are correlated with lower EUIs in New York City office buildings. The program benchmarks the energy efficiency of a specific building against other similar buildings and rates the building on a scale from 1 to 100 , with 100 indicating a high level of comparable energy efficiency. In addition to suggesting that higher ratings are, on average, identifying more energy efficient buildings, a linear regression suggests a difference between taller and low-rise buildings. Each subsequently taller bin has a higher average EUI for the same rating. Each bin follows this trend except buildings with 30 39 floors, which deserves further investigation. Another noteworthy characteristic is the similar slope of every linear regression except two bins, 30 39 and greater than 50 floors. These similar slopes suggest that the average decrease in EUI with ENERGY STAR rating is fairly uniform across most building heights. One plausible explanation for the divergence from these similar slopes for taller buildings is the lack of benchmarking data for large buildings, which is discussed in a later section. Although more data and further investigation will illuminate stronger conclusions, the current trend in New York City helps the firm better inform clients in tall or low-rise buildings, who are seeking an ENERGY STAR rating.

\section{National Data for Perspective Beyond Buildings}

Publicly available building energy data impact more than the design of single buildings. It also can help inform the design of neighborhoods and cities. A growing body of research suggests that large cities not only use resources more efficiently than smaller ones, but also lead to higher productivity $[13,14]$. This

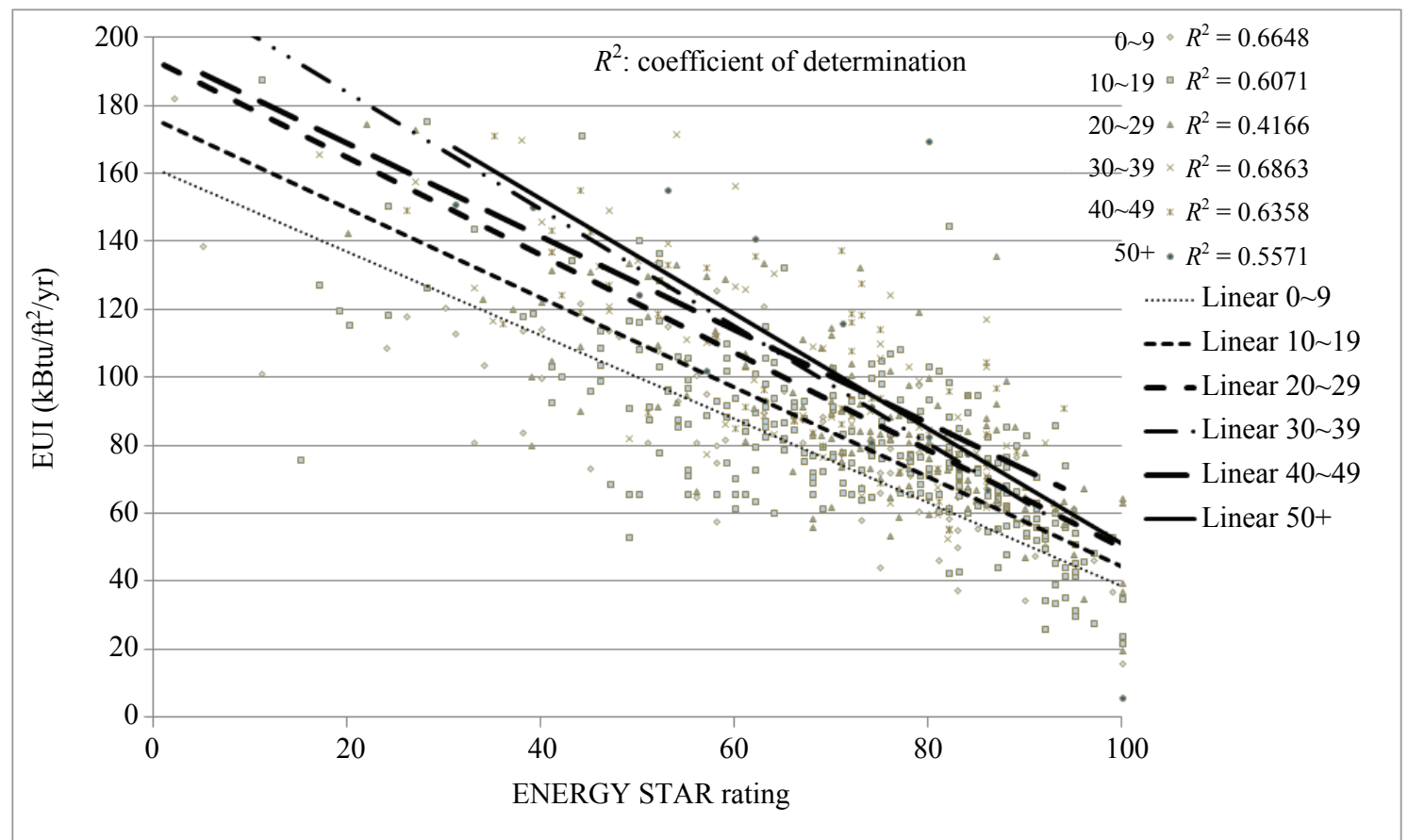

Fig. 4 EUI (units in $\mathrm{kBtu} / \mathrm{ft}^{2} / \mathrm{yr}$ ) plotted as a function of ENERGY STAR rating for various building heights with linear regressions fitted to each bin of heights. 
phenomenon has been quantified around the world, while in the absence of binding global climate change policies, cities are adapting to perform better than nations in per capita greenhouse gas emissions. Per capita emissions in New York City are only $29.7 \%$ of those in the United States as a whole [15]; Those in Rio de Janeiro are only $28.0 \%$ of those of Brazil as a whole [16]; And those in Barcelona are only 33.9\% of those of Spain as a whole [17]. To add to this research from a slightly varied perspective, the firm uses publicly available data to investigate the impact of cities on quality of life.

Life expectancy is a well-documented and relatively consistent metric of quality of life. In this study, life expectancy data are collected from the Institute for Health Metrics and Evaluation from 2009 and made accessible through the measure of America organization [18]. It is used to correlate life expectancy to various developmental and environmental parameters: mean income per capita, education index and carbon emissions per capita. Mean income per capita data are expressed as 2010 US dollars and were collected between 2005 and 2009 by the US Census Bureau [19]. Education index is based on two indicators: school enrollment of children, which is weighted by a factor of one-third, and educational degree attainment of people 25 years and older, which is weighted by a factor of two-thirds [18]. Carbon use per capita data account for the carbon emissions associated with residential and transportation sectors in 100 largest US cities [20,21]. A rigorous methodology is used to collect, analyze and normalize the carbon emissions data that originate with actual energy sold by all utilities for residential energy and vehicle-miles traveled as reported by the HPMS (Highway Performance Monitoring System) maintained by the Federal Highway Administration [20, 21].

Life expectancy depends on too many factors to fully explore in this paper. Moreover, these other factors are not all properly controlled in the obtained data. Nonetheless, correlations between life expectancy and the considered developmental and environmental parameters can still provide insightful relationships. Income and education are commonly known to impact life expectancy, thus the coefficient of determination $R^{2}$ between these two factors and life expectancy should provide a baseline correlation, to which other factors can be compared. A city's per capita carbon footprint provides the strongest linear correlation to life expectancy with an $R^{2}$ of 0.34 , as shown in Fig. 5, which beats out other factors like education index and income that have an $R^{2}$ of 0.22 and 0.30 , respectively. While causality is not considered in this study, the connectivity of cities may impact their inhabitants' life span. Increased physical activity and greater concentrations of world-class medical care may extend the lives of city dwellers who tend to have smaller carbon footprints.

This type of research adds to the body of work used by the firm to inform the design of cities and neighborhoods. Although the dataset is restricted to the US and provides a limited view to the myriad factors impacting life expectancy, it adds another piece to the larger body of work used to help shape firm values.

\section{Conclusions}

Publicly available data are continuing to grow but provide little value on its own. This paper presents some of the ways a large design firm which engages this data to inform design practices through a very select number of applications. A more exhaustive list is outside the scope of this paper, which has focused on using publicly available data to inform design practices.

An internal high performance design reporting program leverages CBECS data to compare projects around the world and spark best-practice conversations throughout the firm.

Benchmarking data from New York City help validate an internal tall building energy framework, particularly how tall buildings tend to have higher EUIs until they reach 30 stories, at which point an EUI plateau 


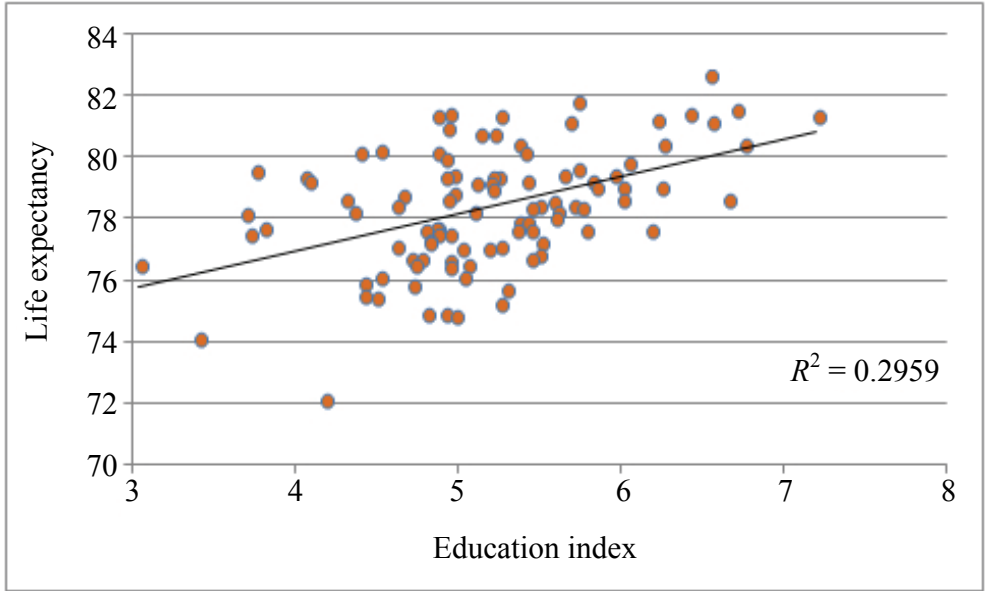

(a)

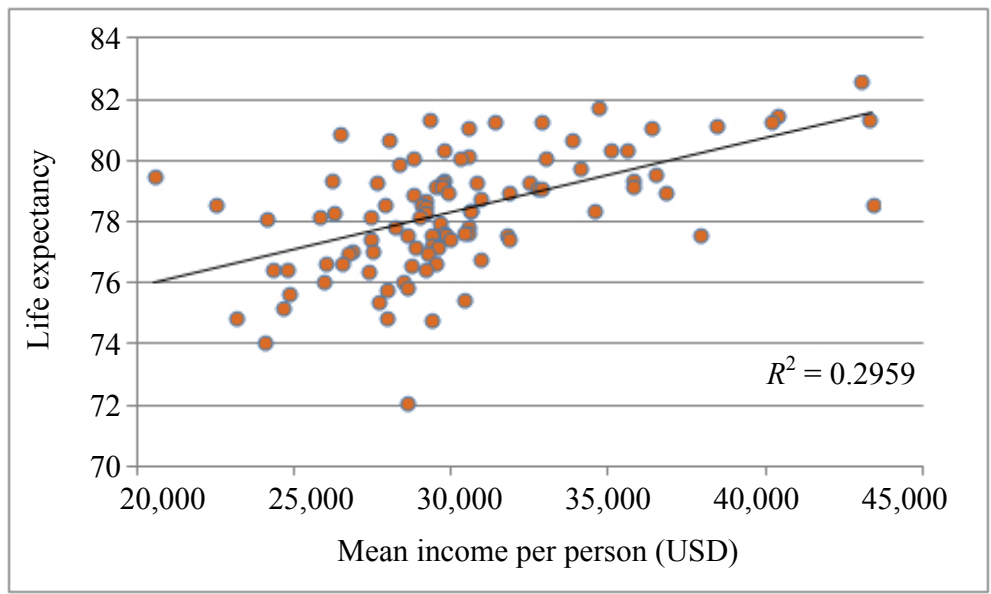

(b)

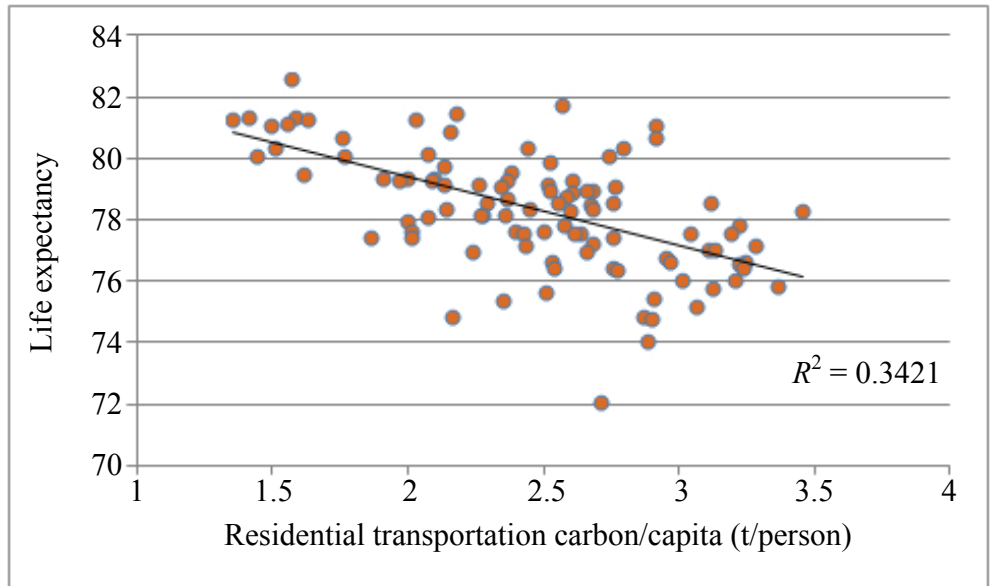

(c)

Fig. 5 Average EUI (units in $\mathrm{kBtu} / \mathrm{ft}^{2} / \mathrm{yr}$ ) of all New York office buildings reported by the City of New York as a function of total number of floors: (a) educational index; (b) mean income per person; (c) residential/transportation carbon/capita.

is reached. The New York City data also provide key insights into relevant trends in the ENERGY STAR program: Taller buildings obtain higher ENERGY
STAR ratings in New York City for a given EUI than shorter buildings, which may stem from the sparse large-building data in the CBECS dataset. 
Lastly, per capita energy usage data are used in conjunction with life expectancy, mean income and education data to add to the body of work that informs neighborhood and city design.

These examples demonstrate a few simple ways that publicly available data can inform design at a large architecture firm.

\section{References}

[1] ENERGY STAR. 2014. "US Environmental Protection Agency and US Department of Energy." ENERGY STAR. Accessed December 15, 2014. http://www.energys tar.gov.

[2] US EIA (United States Energy Information Administration). 2003. CBECS (Commercial Buildings Energy Consumption Survey). Washington, D.C.: US Department of Energy.

[3] CCHRB (Chicago Committee on High Rise Buildings). 2014. Existing High-Rise Buildings-Refurbish, Repurpose or Replace?. Chicago: CCHRB.

[4] Dobbs, R., Remes, J., Manyika, J., Roxburgh, C., Smit, S., and Schaer, F. 2012. Urban World: Cities and the Rise of the Consuming Class. Washington, D.C.: McKinsey Global Institute.

[5] The City of New York. 2013. "Green Buildings and Energy Efficiency: Benchmarking Scores and Reports." The City of New York. Accessed September 26, 2013. http://www.nyc.gov/html/gbee/html/plan/1184_scores.sht $\mathrm{ml}$.

[6] NYCDCP (New York City Department of City Planning). 2013. "Bytes of the Big Apple ${ }^{\mathrm{TM}}$." Accessed September 26, 2013. http://www.nyc.gov/html/dcp/html/bytes/appl byte.shtml.

[7] ENERGY STAR. 2013. Portfolio Manager ${ }^{\circledR}$ Technical Reference. Washington, D.C.: US Environmental Protection Agency and US Department of Energy.

[8] ASHRAE (American Society of Heating, Refrigeration and Air Conditioning Engineers). 2009. ASHRAE Fundamentals. Atlanta: ASHRAE.

[9] Calhoun, K., and Torbert, R. 2013. The Bank of America Tower-What Is and What Could Have Been. New York: Rocky Mountain Institute.
[10] Baumgartner, S., Coleman, J., and Aboff, A. 2013. "Linking NYC Energy Database to Tenant Contribution to Economy." Presented at 2013 Greenbuild International Conference and Expo (Greenbuild 2013), Philadelphia, USA.

[11] New York City. 2013. A Greener, Greater New York. New York City Local Law 84 Benchmarking Report September 2013, New York City.

[12] Leung, L., and Ray, S. D. 2013, "Low-Energy Tall Buildings? Room for Improvement as Demonstrated by New York City Energy Benchmarking Data." International Journal of High-Rise Buildings 2 (4): 285-91.

[13] West, G. B., Brown, J. H., and Enquist, B. J. 1997. “A General Model for the Origin of Allometric Scaling Laws in Biology." Science 276 (5309): 122-6.

[14] West, G. B., Brown, J. H., and Enquist, B. J. 2001. "A General Model for Ontogenetic Growth." Nature 413 (6856): 628-31.

[15] New York City PlaNYC. 2007. Inventory of New York City Greenhouse Gas Emissions. New York: Mayor's Office of Operations, New York City.

[16] Dubeux, C., La Rovere, E. 2007. "Local Perspectives in the Control of Greenhouse Gas Emissions-The Case of Rio de Janeiro." Cities 24 (5): 353-64.

[17] Baldasano, J., Soriano, C., and Boada, L. 1999. "Emission Inventory for Greenhouse Gases in the City of Barcelona, 1987 1996." Atmospheric Environment 3: 3765-75.

[18] Social Science Research Council. 2011. "Mapping the Measure of America. 2010-2011 Dataset." Social Science Research Council. Accessed December 2, 2013. http://www.measureofamerica.org.

[19] US Census Bureau. 2009. American Community Survey 2005 2009, Table B20017. Washington, D.C.: US Census Bureau.

[20] Brown, M. A., and Logan, E. 2008. The Residential Energy and Carbon Footprints of the 100 Largest U.S. Metropolitan Areas. Working Paper No. 39, Georgia Tech Ivan Allen College, School of Public Policy Working Paper Series.

[21] Southworth, F., Sonnenberg, A., and Brown, M. A. 2008. The Transportation Energy and Carbon Footprints of the 100 Largest US Metropolitan Areas. Working Paper No. 37, Georgia Tech Ivan Allen College School of Public Policy Working Paper Series. 